\title{
Marcel Duchamp
}

\section{Lady Dada}

\begin{abstract}
Vor genau 100 Jahren begann ausgerechnet in der konservativ-bürgerlichen Schweiz die wahrscheinlich radikalste und antibürgerlichste Kunstbewegung überhaupt. In der Züricher Spiegelgasse eröffnete im Februar 1916 das Café Voltaire. Es war die Geburtsstunde des Dadaismus. Dada war Anarchie pur, ein Labor für höheren und niederen Blödsinn, ein Aufruhr gegen jede Art von Konvention. Ob Religion, Tradition oder Vaterland - nichts war den Dadaisten heilig. Nicht einmal die Mona Lisa.
\end{abstract}

$\mathrm{D}$ ada sprengte nicht nur alle gesellschaftlichen Konventionen, es rebellierte auch gegen die traditionellen Grenzen der Kunst. Im Café Voltaire trug Dada-Gründer Hugo Ball seine sinnfreien „Lautgedichte“ vor und verkleidete sich dabei als Bischof im kubistischen Kostüm. Seine Partnerin Emmy Hennings interpretierte Debussy am Klavier und legte gleich darauf einen „Negertanz" aufs Parkett. An den Wänden hingen hauptsächlich Kollagen und Nonsenswerbung. Dazu passten die Arbeiten von Marcel Duchamp natürlich hervorragend. Der hatte kurz zuvor mit seinen Readymades die Kunstwelt revolutioniert. Für eine Skulpturenausstellung schraubte er einfach einen Flaschentrockner beziehungsweise ein Urinal auf ein Podest und signierte das Ganze mit seinem Namen. Die ewige Frage, was Kunst denn nun eigentlich sei, war damit ein für alle Mal beantwortet. Kunst ist, was der Künstler zu Kunst erklärt. Und wenn ein Künstler auf eine billige Mona-Lisa-Reproduktion ein dümmliches Bärtchen kritzelt, dann ist das eben auch Kunst. Den Dadaisten leuchtete das sofort ein.

Der Sommer der Anarchie in Zürich dauerte allerdings nicht lange. Bereits nach fünf Monaten schloss das Café Voltaire wieder seine Tore. Dada allerdings wirkte weiter. Die Künstler, die in Zürich den Un-Sinn zum Lebenskonzept verklärt hatten, trugen ihre Gedanken in alle Welt. Und sie beeinflussten auch die nachfolgenden Kunstströmungen. Vom Surrealismus über die Fluxusbewegung bis zu modernen Performanceauftritten - bei Dada ist bereits alles angelegt. Und wenn heute ein internationaler Megastar wie Lady Gaga auf den MTV Music Awards in einem Kleid aus rohen Rindfleisch erscheint, dann weiß der Kenner: Die Pop-Diva hat sich nicht nur bezüglich ihres Namens von den Züricher Anarchokünstlern beeinflussen lassen.

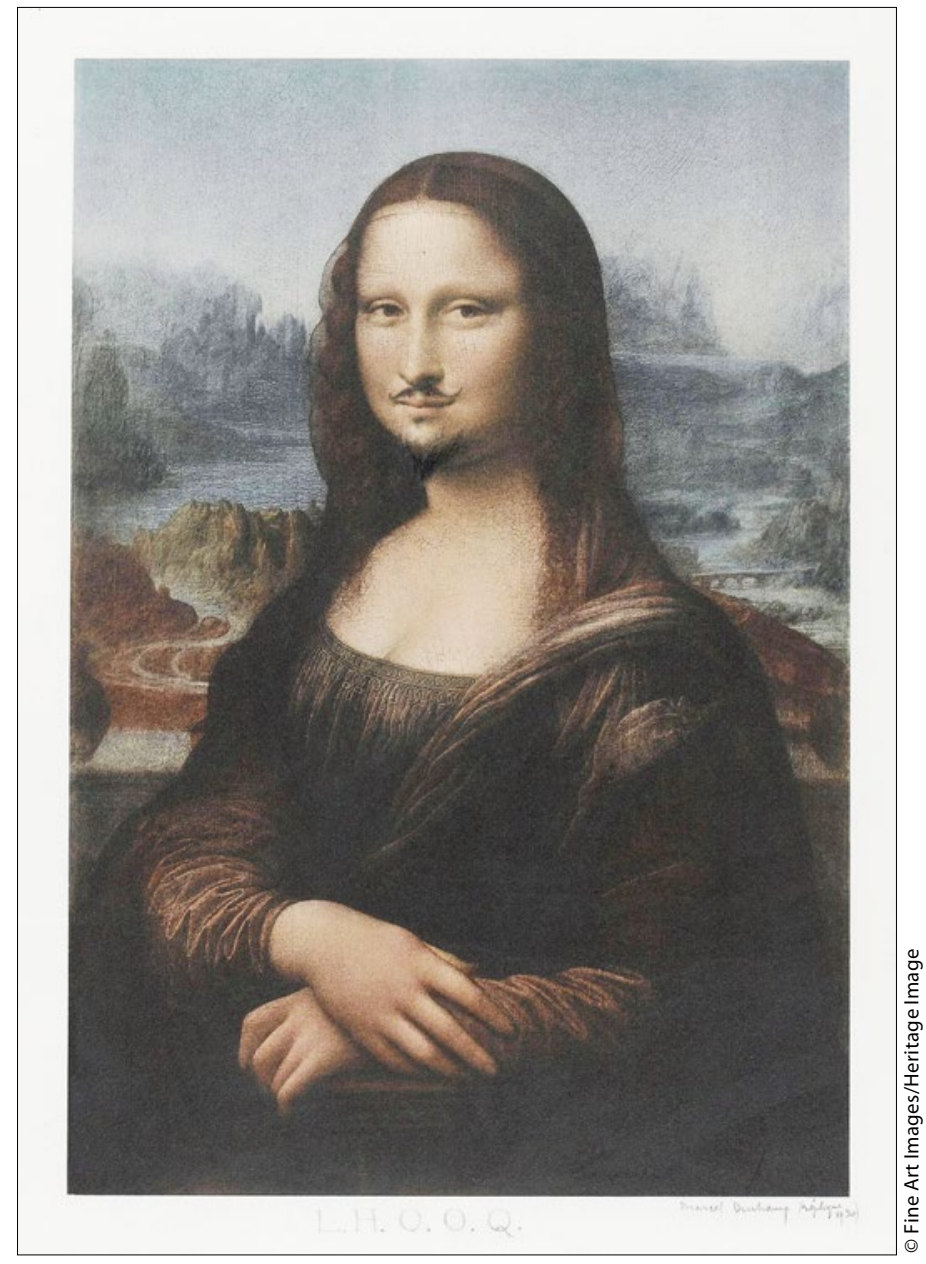

„L.H.O.O.Q.", Mona Lisa, 1919, Marcel Duchamp (1887-1968)

Bleibt noch die Frage: Wofür steht das kryptische L.H.O.O.Q.? Marcel Duchamp hat dazu einmal einen Hinweis gegeben. Man solle doch die Buchstaben einfach französisch aussprechen. Dann kommt, zumindest wenn man vorher einiges getrunken hat, so etwas Ähnliches heraus wie: Elle a chaud au cul (Sie hat Hitze im Hintern). Das wiederum ist in unserem linksrheinischen Nachbarland eine einigermaßen vulgäre Bezeichnung für eine Frau, deren sexuelles Interesse das Normalmaß deutlich übersteigt.

Hätten wir das auch geklärt.

Prof. Dr. med. Bernd Kleine-Gunk, Fürth 